\title{
EDITORIAL
}

\section{Creative tourism: the issues of philosophy, sociology and communication}

The present issue is devoted to the topic of creative tourism reviewed from the perspectives of philosophy, sociology and communication. The conception of creative tourism is based on criteria of quality, originality, innovation and sustainability that suppose better access to culture or history, and engagement in the real cultural life of urban spaces. Creative tourism is a new generation of tourism. This kind of new tourism values and enriches cultural, personal and natural resources rather than manipulates and exploits it, which usually happens in the case of traditional tourism. Main virtues of creative tourism are diversification of tourist offers; optimisation of tangible and intangible heritage; authenticity and sustainability as they use creativity as the main resource; optimal spatial distribution of "tourist attractions"; intangible heritage recovery; etc.

Creative tourism involves various interactions. A traveller has an emotional, social, and participative interaction with the visited place, its living culture, and local inhabitants. Creative tourism invites us to become a part of the visited culture instead of watching it from a distance. For example, such traveller communities as CouchSurfing are not only a part of creative tourism, but also provide a possibility to stay with local people, instead of hotels. Travellers discover different traditions and lifestyles, see the everyday life in its true colours rather than its version, specially tailored and presented for a typical tourist. Creative tourism means to be involved in the visited culture, to go beyond the facades and to discover the ordinary life of locals instead of being limited to touristic spaces of visited cities.

The present issue shows how the philosophical and sociological perspectives on creative tourism unveil various topics and aspects. A phenomenological approach is particularly fruitful for the analysis of creative tourism. This analysis is based on personal experience, which is acquired here and now, and is based on openness toward others (acceptance of different values, lifestyles, etc. as equal and autonomous). Probably, that was the reason behind the acceptance of the editor's invitation by two most famous living philosophers of Lithuanian origin to write papers for this issue. Algis Mickūnas and Alphonso Lingis mainly deal with the phenomenological methodological approach. Their papers are based on the authentic experience of scholars who have long-term practice in various fields of creative tourism.

The present issue consists of six papers grouped into three thematic sections. The first section presents the reader with meta-discourses on travelling. Both authors have a different approach to the very concept of meta-discourse. Mickūnas presents an excellent paper "Philosophy and Time Travel". He discusses the concept of time-travel through awareness of time and aspects of the pre-temporal life of awareness. The author discloses philosophical time travel to engage in a dialogue with others. In her paper 
"Augmented Reality as Means of Travel - When Picture Changes the Place", Elena Sakalauskaite deals with a relevant and particularly interesting field of new media - the augmented reality. The author shows how space is used to produce travel experience. She analyses some videos about the building of Vilnius Cathedral. The paper demonstrates that despite differences, each projection has its place at a specific time (around Christmas) and is performed at the same place (Vilnius Cathedral). Meta-discourses of these authors invite us for a time travel (to the very essence, to pre-temporal life), or to reality (when the surrounding world and the digital reality coexist and overlap). This journey shows us various aspects of creative tourism.

In the second part, research topics are centred on the living world as the environment for travelling. The paper by Lingis "Building for Movement" is based on the concept of Martin Heidegger's understanding of human existence as a dwelling that embodies and discloses the surrounding world, which is equally required as an extension of that building. The author moves through various layers of human dwellings, from huts through mansions, to high-rises and gated communities. He questions the stereotype that humans are the privileged species capable of sedentary life in their dwellings. The concept of creative tourism in this paper is virtuously unveiled through new environmental movements. These movements help humans to live in peace with nature, in a more ecological way. The authors invite readers to get away from the closed "dwellings" to open skies, teeming jungles, nearby or far-off forests, mountains, glaciers, beaches, and oceans. John W. Murphy and Christian A. Schlaerth analyse the topic of tourism at the museum and show how they remove knowledge from the living world and create a sterile image of culture. The authors discuss how a trend may be reversed and how museums may restore the original function of being a relevant part of culture tourism and having an active impact on the restoration of the living world. Creative tourism supposes that tourists are no longer simple visitors as they can be integrated into the real meaning of culture, which they can explore and create new, possibly contentious storylines.

The third part of the present issue deals with public and cross-cultural cases of travelling. In her paper "Revitalization of Public Places in the Context of Creative Tourism", Vaida Rabazauskaite discusses the concept of creative tourism. She analyses creative approaches and tourism resources and sets the role of a tourist as a co-producer in the process of cultural production and an active contributor to everyday life. The author investigates how creative workshops may help in the process of revitalisation of creative spaces. She looks at possibilities for active participation, which would involve both tourists and citizens. The role of tourism is defined as an active participation in cultural processes, a way of revitalisation of public spaces. Vilmante Liubinienè and Daniel Persson Thunqvist presented the paper "Media Literacy and Digital Divide: A Cross-Cultural Case Study of Sweden and Lithuania". They analyse the topic of the inclusion and exclusion when it comes to the media literacy and the digital divide. Also, they investigates cross-cultural similarities and differences, and discusses various country-level factors.

Saulius Keturakis in his article "On the Road with a Smartphone" analyses the contemporary phenomenon of traveling using smart phones and discuses the multidimentional experiences of these travels under the conditions of mobile technologies. 